\title{
ACHIEVING SUSTAINABLE GAINS IN HAPPINESS: CHANGE YOUR ACTIONS, NOT YOUR CIRCUMSTANCES ${ }^{\star}$
}

\begin{abstract}
Although attaining happiness is a nearly universal goal, surprisingly little research has focused on how happiness can be increased and then sustained. Three studies test predictions of a model (Lyubomirsky et al., 2005) positing that sustainable happiness is possible through intentional activity changes, more so than through circumstantial changes. Study 1 shows that less hedonic adaptation is reported in response to activity changes than to circumstantial changes. Study 2 tests a dynamic process model, showing that while both positive activity changes and positive circumstantial changes predict rank-order increases in subjective well-being from Time 1 to Time 2, only activity changes predict maintained gains at Time 3 . Study 3 replicates the Study 2 findings and extends them to psychological well-being (Ryff and Keyes, 1995). Implications for positive psychology and "the pursuit of happiness" are discussed.
\end{abstract}

KEY WORDS: happiness, hedonic adaptation, set point, well-being.

\section{THE "PURSUIT OF HAPPINESS"}

The "pursuit of happiness" is an American cultural obsession, beginning with the Declaration of Independence, where it is pledged as an important right for all citizens. Today, happiness remains a topic of tremendous interest for groups as diverse as philosophers, policy makers, and poets, and, increasingly, for economists, popular psychology writers, and happiness "coaches." As any bookstore visitor can attest, rows of self-help books in any major bookstore are committed to the literature on happiness. Furthermore, the pursuit of happiness is becoming

$\star$ This work was supported in part by grants from the Positive Psychology Network. 
ever more global, as people seek to realize the promises of capitalism and political freedom (Freedman, 1978; Diener et al., 1995).

Reflecting this burgeoning interest, research on subjective well-being (SWB) has exploded over the last 20 years, with hundreds of citations per year. A variety of correlates of happiness, positive mood, and life satisfaction have now been identified (DeNeve and Cooper, 1998). For example, well-being has been shown to be associated with certain demographic variables (e.g., Argyle, 1999; Diener et al., 1999), personality traits and attitudes (e.g., Diener and Lucas, 1999), and goal characteristics (e.g., McGregor and Little, 1998).

Ironically, however, very few of these studies speak to a central assumption of the "American dream" - namely, the idea that one can achieve and maintain relatively greater well-being, compared to an earlier period in one's life. At least three waves of data are required to test this assumption, but the vast majority of studies of well-being have used data from only one time period. In other words, most studies have been cross-sectional rather than longitudinal. Thus, researchers still have little understanding of how well-being varies over time, and what factors influence these changes (but see Atkinson, 1982, for an early discussion of this issue, or more recently, Lucas et al., 2003). In addition, little is known about what factors, if any, might bring about stable changes in levels of well-being, either positive or negative.

\section{Reasons for Pessimism Regarding Sustainable Increases in Well-Being}

Doubtless, part of the reason researchers have neglected to study sustainable well-being change is the difficulty of conducting longitudinal and prospective studies. However, we believe another reason for this neglect is the considerable scientific pessimism over whether it is even possible to achieve sustainable increases in happiness. One source of pessimism is the idea of a genetically-determined set point for happiness. Lykken and Tellegen (1996) have provided evidence, based on behavior-genetic studies, that the heritability of well-being may be as high as $80 \%$ (although $50 \%$ is a more widely accepted figure; Diener 
et al., 1999). Regardless of the exact coefficient, the large magnitude of these estimates suggests that each person has a chronic or characteristic level of happiness, from which it will be difficult, if not impossible, to depart. Thus, although there may be substantial variation around this baseline level in the short-term, in the long-term, people perhaps cannot help but return to their set point: "What goes up must come down" (e.g., Headey and Wearing, 1989).

A second source of pessimism comes from the concept of hedonic adaptation (Brickman and Campbell, 1971; Frederick and Loewenstein, 1999), which suggests that gains in happiness are impermanent, because humans so quickly adapt to change (see also Kahneman, 1999; Scitovsky, 1976). That is, although new circumstances may cause temporary increases in happiness or sadness, people rapidly adjust, and the effect of these new circumstances on their well-being then quickly diminishes or even entirely disappears. For example, Brickman et al. (1978) showed that recent lottery winners were no happier than controls and, furthermore, that recent victims of paralysis were not as unhappy as one would expect (see also Dijkers, 1997).

\section{Reasons for Optimism Regarding Sustainable Increases in Well-Being}

Do the arguments for pessimism described above lead to the conclusion that the pursuit of happiness is fruitless - that, rather than chasing happiness, people may be better off by simply accepting their current personality and happiness levels (McCrae and Costa, 1994)? For three reasons, we believe not. First, some researchers have had preliminary success, albeit short-term, in using interventions to enhance happiness (e.g., Schulz, 1976; Fordyce, 1977, 1983; Lichter et al., 1980; Fava, 1999; Sheldon et al., 2002). The potential of happiness-increasing interventions is further demonstrated by recent research showing that practicing certain virtues, such as gratitude (Emmons and McCullough, 2003), forgiveness (McCullough et al., 2000), and thoughtful self-reflection (King, 2001; Lyubomirsky et al., 2004) can bring about enhanced well-being.

Second, many different motivational factors have been associated with well-being, factors that are presumably amenable 
to some volitional control. Examples of motivational factors include the successful pursuit of life goals that are intrinsic in content (e.g., Kasser and Ryan, 1993, 1996), concordant with an individual's interests, values, and motives (Brunstein et al., 1998; Sheldon and Elliot, 1999), and internally consistent (e.g., Emmons and King, 1988; Sheldon and Kasser, 1995). Thus, one might find greater happiness by choosing particular kinds of goals.

Third, a variety of cognitive factors have been linked to wellbeing, factors that are presumably also amenable to some volitional control. These include pausing to count one's blessings (Emmons and McCullough, 2003), eschewing social comparisons and contingent self-evaluations (e.g., Lyubomirsky and Ross, 1997), and choosing to feel a sense of optimism or efficacy regarding one's life (Taylor and Brown, 1988; Seligman, 1991; Bandura, 1997). Thus, by changing one's patterns of thought and ways of construing events, one might find greater happiness.

To summarize, there appears to be a paradox: Some theoretical perspectives and empirical data imply that well-being can be increased, while other theories and data suggest that it cannot. How can these conflicting perspectives on the possibility of lasting happiness change be resolved? Also, if increases in happiness are indeed possible, what kinds of circumstances, actions, or habits of mind are most likely to bring gains, especially gains that can be maintained?

\section{A New Model of Longitudinal Well-Being}

In this article, we test important predictions from a new model of longitudinal well-being recently advanced by Lyubomirsky et al. (2005). The model specifies three major determinants of well-being at time $t$ : (1) the person's genetic set point or set range (which reflects personality and temperament), (2) the person's current circumstances (demographic, geographic, and contextual), and (3) the person's current intentional activities (behavioral, cognitive, and conative). We focus on these three major categories because they have historically received the majority of attention in the well-being literature (Diener et al., 1999), and because they allow consideration of several important 
issues and paradoxes, such as the question of whether it is even possible to "become happier" given strong genetic influences on happiness, the question of why past well-being research has found such weak associations between demographic/circumstantial variables and happiness, and the question of how a person might appropriately take action to "pursue" happiness.

We assume that the set point remains constant across the lifespan, reflecting the person's basic temperament, constitution, and personality traits. Because the factors that determine the set point (i.e., the person's basic temperament and personality traits) are, by definition, stable, they should have little or no impact on variations in well-being over time. Thus, the set point is not formally measured or modeled in the current research. Instead, we assume that it is best estimated by the person's average well-being score (Lykken, 1999) and, furthermore, that it accounts for the considerable expected longitudinal stability in well-being. Although some personality measures may tap the set point relatively directly, we assumed that including such constant measures in our models would not affect the dynamic patterns observed.

What then accounts for variations in an individual's level of well-being? Our model specifies that the person's current circumstances (e.g., his health, income, or the region where he lives) can either add to or detract from his constant set point, as can the person's current intentional activities (e.g., her behavioral activity of exercising regularly, her cognitive activity of trying to accentuate the positive, or her conative activity of trying to gain admission to a professional program). As Lykken (2000) has argued, despite a genetically-determined baseline for well-being, humans are capable of increasing their happiness relative to this baseline through various "happiness makers." In this article, we subdivide these happiness makers into two types - activitybased and circumstance-based.

As evident from the above descriptions, activity-based changes, by definition, involve continual effort and engagement in some intentional process, whereas circumstance-based changes are, by definition, one-time changes that tend to occur independently of effort and engagement. Of course, the distinction between activity and circumstantial changes may not 
always be clear, as activity may be required to change one's circumstances, and because many circumstances involve activity. Despite these challenges, we attempted to separately measure these two abstract categories, hoping to illustrate with psychometric and hypothesis-confirmatory results that they are valid and important.

A central assumption of Lyubomirsky et al.'s (2005) model is that hedonic adaptation occurs more quickly with respect to circumstantial changes than to activity changes. In other words, the effects of positive circumstantial changes (such as securing a raise, buying a new car, or moving to a sunnier part of the country) tend to decay more quickly than the effects of positive activity changes (such as starting to exercise, changing one's perspective, or initiating a new goal or project). This differential adaptation assumption is rooted in the proposal that circumstances (e.g., salary, car ownership, place of residence) represent relatively static and constant "facts" about one's life. Thus, although changes in circumstances can trigger increases in wellbeing, such boosts tend to be short-lived, because people quickly begin to take those new circumstances for granted and cease to derive positive experiences from them. Indeed, hedonic adaptation to stable situations may explain why life circumstances such as income, health status, and geographic region have been more weakly associated with cross-sectional wellbeing than expected (Diener, 1984; Diener et al., 1999) - in cross-sectional studies, participants are undoubtedly sampled at various lengths of time following the onset of particular circumstances, "watering down" the effects of circumstances, overall.

In contrast, intentional activity focuses a person's energy and behavior in a variety of different ways, leading to a more diverse and varied set of experiences, relative to the experiences produced by circumstances. Also, intentional activity can bring about an expanding array of new opportunities and possibilities, potentially leading to sustained positive effects in the person's life (Fredrickson and Joiner, 2002; Sheldon and Houser-Marko, 2001). Finally, intentional activity can directly counteract the tendency toward adaptation, as people might make the effort to keep varying how and when they engage in 
the activity. These three features of intentional activity should help to forestall adaptation.

In sum, Lyubomirsky and colleagues' (2005) model of longitudinal well-being makes clear predictions regarding what should be found in a three-wave investigation of well-being. Positive circumstantial changes occurring between Time 1 and Time 2 should produce enhanced well-being at Time 2, but this effect should disappear by Time 3, because people quickly adapt to circumstantial changes, and cease to derive positive experiences from them. In contrast, positive activity changes between Time 1 and Time 2 should produce enhanced well-being at both Time 2 and Time 3. This is because changed activities are more likely to continue providing positive experiences over the long-term. These predictions are tested in Studies 2 and 3.

\section{STUDY 1}

In Study 1, we set the stage for the longitudinal test by evaluating an important prediction of Lyubomirsky and colleagues' (2005) model - namely, that hedonic adaptation occurs more rapidly for circumstantial than for activity change. To this end, we asked participants to self-select into one of two groups those who had recently experienced a positive circumstantial change in their lives, and those who had recently experienced a positive activity change. All participants rated various characteristics of the change they had experienced, allowing us to examine between-subject mean differences between the two groups.

In particular, participants were instructed to rate the extent to which they have "gotten used to" their change, and, the extent to which their change "continues to add variety" to their lives. We expected that activity participants would report having adapted less to their change, and would also report deriving more varied experiences from their change. We also asked participants to rate the amount of effort involved in making the change, and the extent to which the change was intentional versus accidental. We predicted that activity change participants would ascribe a greater degree of effort and intentionality to the 
change. Finally, we also asked participants to rate their current levels of positive affect. We reasoned that the activity change participants should be happier (assuming that their change occurred about the same time as that for the circumstantial change participants), because the well-being associated with activity change should not have decayed to the same extent as the well-being associated with circumstantial change.

\section{METHODS}

\section{Participants and Procedure}

Participants were 224 introductory psychology students, 72 men and 152 women. Two different descriptions of the experiment were posted on a web-based sign-up system. One version read: "Please sign up only if there has been some significant positive change in the circumstances of your life since the beginning of the semester, which has given you a boost since it occurred. 'Circumstances' means 'facts' about your life, such as living arrangement, monetary situation, or course-load. For example, you may have moved to a better dorm or better roommate, received an increase in financial support so you can have more fun, or dropped a course that you were really going to have trouble with." The other description read: "Please sign up only if you have adopted some significant positive new goal or activity since the beginning of the semester, which has given you a boost since it occurred. 'Goal/activity' means something you chose to do or get involved in, which takes effort on your part. For example, you may have joined a rewarding new group, club, or sports team, decided on a major or career direction which makes it clear what to focus on, or taken on some other important new project or goal in your life."

In all, 114 students registered for the activity-change condition, and 110 registered for the circumstance-change condition. No participants registered for both sessions. Participants attended group sessions, which included both conditions.

Participants were given a questionnaire to complete upon arriving at the testing room. They were first asked to write a 
paragraph about the most important change that had occurred for them since the beginning of the semester, where the change had to be either a circumstantial or an activity change, as defined by the sign-up criteria. Seventy-eight participants were later excluded (28 in the activity condition and 50 in the circumstantial condition) because, they did not write about the condition into which they had previously selected themselves. We believed this was justified, as we wanted to include only participants who consistently indicated having experienced either one type of change or the other, and exclude participants who may not have read the sign-up criteria or the session instructions carefully. Thus, the final sample consisted of 82 activity participants and 64 circumstances participants. ${ }^{1}$

Not surprisingly, participants wrote about a wide variety of changes. Examples of circumstantial changes included "I learned that I won't have to be in a lottery in order to get in my Broadcast 1 class," "My roommate at the beginning of the semester was a cocaine addict; she is no longer my roommate," "This week I found out that I received a scholarship that I wasn't expecting at all," "My mother was recently diagnosed with brain cancer and a couple of days ago a surgery was performed and everything turned out fine," and "I was recently initiated into my fraternity...I no longer have to worry about initiation requirements." Examples of activity changes included "When I first got here my classes seemed hard and I didn't study as much as I should have. I set myself a goal to study for at least $5 \mathrm{~h}$ a day and now my classes are going a lot better for me," "I enrolled in a class that is helping me to figure out a correct career choice for me," "I used to not ever go to church, but now I am going to Campus Crusade for Christ meetings, and God is more a part of my life than He ever has been," "I have started lifting weights 4 or 5 days a week. This has drastically boosted my energy levels," and "I made a goal for myself that I would get involved and spend mostly all of my free time working on homecoming for my fraternity."

\section{Measures}

After describing the life change, participants made a number of ratings of the particular change they had experienced. First, we 
assessed the extent to which the change had been intentional, and the extent to which the change required effort to bring about. We asked these questions in order to help validate the manipulations, since changes based in volitional activity should be perceived as more intentional and more effortful compared to changes rooted in external facts and circumstances. Specifically, to assess the intentionality of the change, we combined the following two questions: "To what extent was the change your own doing? That is, how much did you bring it about?" and "To what extent did you choose to have this change? That is, how much did you mean for it to happen?" $(\alpha=0.74)$. To assess the degree of effort associated with the change, we combined the following two questions: "How much effort did you have to put into making the change happen?" and "How much effort do you have to put into keeping the change going?" $(\alpha=0.61)$. A 1 (not at all) to 5 (very much) scale was used for each rating.

To assess hedonic adaptation, we used the following question: "To what extent have you gotten used to the change? That is, to what extent do you find that you've become accustomed to it, such that it doesn't give the same boost as before?" To assess experiential variety, we employed the following question: "To what extent is the change something that varies over time - i.e., something that adds variety to your life?" These two variables allowed us to test our primary theoretical hypotheses, relevant to understanding the sustainable effects of activity and circumstantial change upon well-being.

To assess positive mood, we administered the positive affect scale of the PANAS (Watson et al., 1988). This 10-item scale presents a variety of positive mood adjectives, such as "inspired", "alert," and "strong." Participants were asked to rate how the change they wrote about had affected their typical feelings since it occurred, using a 1 (much less of this feeling) to 3 (same) to 5 (much more of this feeling) scale.

Finally, participants rated how long ago the change had occurred, using a scale ranging from 1 (1-10 days ago) to 4 (30 or more days ago). This question was included to evaluate one alternative explanation of any activity versus change effects - 
namely, that the two types of reported change differed in how long ago they had occurred.

\section{RESULTS}

We conducted a series of independent sample $t$-tests to compare the means of the two groups (see Table I). The analyses revealed significant group differences for the intentionality variable, $t(144)=4.31, p<0.01$, such that the activity group judged the change in their lives as relatively more of a product of their own intentions. A significant mean difference was also found for the effort variable, $t(144)=3.91 p<0.01$, such that the activity group mean was higher. Again, these results may be viewed as validating our measures of activity-based versus circumstance-based life change as, according to our assumptions, changes rooted in volitional activity should be perceived as more intentional and more effortful compared to changes dependent on external facts and circumstances.

We then turned to our theoretically derived hypotheses. As expected, the activity group reported acquiring much more varied experiences from their change, $t(144)=2.46, p<0.05$, whereas the circumstances group reported a relatively stronger sense of "having gotten used to" their change, $t(144)=3.67$, $p<0.01$. Furthermore, relative to the circumstance group, the activity group reported that the positive change they had

TABLE I

Mean differences between the activity change group and the circumstantial change group (Study 1)

\begin{tabular}{lll}
\hline & Activity change & Circumstantial change \\
\hline Validity checks & & \\
Intentionality & 4.30 & 3.68 \\
Effort & 3.95 & 3.31 \\
Hypothesis tests & & \\
Habituation & 2.96 & 3.57 \\
Variety & 3.43 & 2.90 \\
Positive affect & 4.03 & 3.67 \\
\hline
\end{tabular}

Note: All group differences are significant at the 0.01 level or higher. 
experienced had produced a greater increase in positive affect, $t(144)=4.25, p<0.01$. Given that the scale referred to change in affect with " 3 " representing no change, and also the fact that both means were greater than 3.5, it appears that both groups indeed experienced a "boost" from their respective change. However, the boost was not as large, or as long-lasting, for the circumstance change group (see Table I).

Might the group differences reported above have resulted because activity changes had generally occurred more recently than circumstantial changes? No, as the two groups did not differ on this variable, $t(144)=1.43, n s$. The sample mean for the "time elapsed" variable was 2.92, indicating that participants' changes occurred approximately 30 days ago, on average.

Finally, although some significant main effects of gender emerged in some of the analyses reported above, gender did not interact with change-type, suggesting that the processes specified by our model are the same for both sexes.

\section{BRIEF DISCUSSION}

Study 1 provided preliminary evidence for our dynamic process model, by supporting a central assumption of that model - that circumstantial changes are characterized by more hedonic adaptation, and, conversely, that activity changes give rise to more experiential variety. In addition, Study 1 confirmed that activity changes are more intentional and effortful. Finally, this study revealed that activity change participants experienced greater positive affect as a result of their change, compared to the circumstance change participants. Given the fact that intentional activities are more volitional in nature and less susceptible to hedonic adaptation, it appears that such activities may indeed offer a promising route to "the pursuit of happiness."

One limitation of Study 1 is that it was cross-sectional, not longitudinal. Thus, Study 1 did not address change in wellbeing, the central outcome in our model. Also, this study could not address the possibility that stable personality variables account for the patterns observed - that is, whether participants' willingness to self-select into one group over another reflects 
some individual difference that also happened to be associated with the concurrent outcome measures. To remedy these limitations, we conducted a longitudinal study, which gave us an opportunity to assess concrete change in well-being, as well as to partial out stable personality differences that should have equal influence at every measurement period.

\section{STUDY 2}

Study 2 was designed to provide a direct test of our dynamic process model, by comparing the longitudinal effects of circumstantial change and activity change on gains in well-being in a three-wave study of a large sample of individuals. Well-being was measured at all three waves, as were positive activity changes and positive circumstantial changes occurring between Times 1 and 2. Thus, unlike the previous study, this study assessed the magnitude of activity and circumstantial changes within the same participants, allowing us to use a simultaneous regression strategy. We hypothesized that both types of change would have effects on well-being at Time 2 , but that only activity change would still have effects at Time 3 . We also examined mean-level changes in well-being (relative to the participants' own past levels), in addition to rank-order shifts in well-being (relative to others in the sample), as these two types of change are orthogonal and perhaps equally important means of evaluating temporal changes in well-being.

\section{METHOD}

\section{Participants and Procedure}

Participants were 669 students in psychology classes at a large state university, 249 men and 420 women, who took part in exchange for extra credit. The data were collected during three different semesters, from three separate samples, using the same study design in each case. Because some mean differences emerged among samples, we control for sample membership using two dummy variables in our primary hypothesis tests, below. 
Students completed three in-class questionnaires, one near the beginning of the semester (Time 1), one near the mid-point of the semester ( 6 weeks later; Time 2), and one near the end of the semester (12 weeks later; Time 3). Participants rated recent activity and circumstantial changes within their lives at Time 2, and rated their current well-being at Times 1, 2, and 3.

\section{Measures}

To extend our assessment of well-being, we employed the full 20-item PANAS (Watson et al., 1988). This enabled us to examine negative affect (NA; i.e., "irritable," "ashamed"), as well as positive affect (PA). Alpha coefficients for negative affect ranged between 0.79 and 0.87 over three assessments, and alpha coefficients for positive affect ranged between 0.82 and 0.85 . We also administered the 5-item Satisfaction With Life Scale (SWLS; Diener et al., 1985), to assess this more cognitive aspect of wellbeing (e.g., "The conditions of my life are excellent"; alphas ranged between 0.81 and 0.86). Together, these three variables - PA, NA, and life satisfaction - form the core of subjective well-being, according to Diener (1984, 1994). At each assessment, participants rated their well-being "right now in your life," using 1 (not at all) to 5 (very much) scales. To provide the most reliable measure of well-being, we also created an aggregate SWB variable at each time period, by summing PA and life satisfaction and subtracting NA. This procedure has been used successfully in many past studies (e.g., Diener, 1994; Elliot and Sheldon, 1996; Sheldon and Elliot, 1999; Sheldon and Kasser, 1995). Supporting its use, factor analyses of PA, life satisfaction, and NA (reversed) revealed a single factor at each time period, which accounted for $54 \%, 57 \%$, and $55 \%$ of the variance, respectively.

In order to assess activity change and circumstantial change, we used the same two paragraphs that were employed to recruit the Study 1 participants. Specifically, at Time 2, the participants in Study 2 rated the extent to which they had experienced both an activity change and a circumstantial change since Time 1, as defined by those two paragraphs $(1=$ no positive change; $5=$ much positive change $)$. Again, we intended to use these ratings in simultaneous regressions, so 
that we could compare the relative impact of activity change and circumstantial change.

\section{RESULTS}

\section{Preliminary Analyses}

Table II presents descriptive statistics for the primary study variables. Participants reported higher levels of positive activity change than positive circumstantial change, $t(668)=9.36$, $p<0.01$. Also, there was a significant sample-wide decline in aggregate SWB from Time 1 to Time $2, t(668)=5.45, p<0.01$, a decline that was also reflected in the comparison between Time 1 and Time $3, t(668)=4.32, p<0.01$. These effects were driven by significant decreases in PA and significant increases in NA between Time 1 and Times 2 and 3. As a final preliminary analysis, we correlated the activity change and circumstantial change variables, finding an association of $0.31(p<0.01)$. This association indicates that there is some overlap between the two constructs, but not a large amount; thus, it is reasonable to examine their simultaneous influence.

TABLE II

Descriptive statistics for Study 2 measures

\begin{tabular}{lll}
\hline & Mean & Standard deviation \\
\hline Positive activity change & 3.39 & 1.08 \\
Positive circumstantial change & 2.92 & 1.10 \\
T1 Aggregate well-being & 4.93 & 1.66 \\
T2 Aggregate well-being & 4.67 & 1.67 \\
T3 Aggregate well-being & 4.69 & 1.73 \\
T1 Positive affect & 3.59 & 0.66 \\
T2 Positive affect & 3.55 & 0.65 \\
T3 Positive affect & 3.49 & 0.71 \\
T1 Negative affect & 2.09 & 0.76 \\
T2 Negative affect & 2.28 & 0.76 \\
T3 Negative affect & 2.27 & 0.77 \\
T1 Life satisfaction & 3.44 & 0.82 \\
T2 Life satisfaction & 3.40 & 0.79 \\
T3 Life satisfaction & 3.47 & 0.83 \\
\hline
\end{tabular}




\section{Rank-Order Shifts}

Next, we tested our hypothesis that both positive activity change and positive circumstantial change would predict changes in well-being from Time 1 to Time 2. Specifically, we regressed each Time 2 well-being variable (SWB, PA, NA, and life satisfaction) upon the corresponding Time 1 well-being variable and also the two change variables. Table III provides the standardized coefficients that resulted. As expected, Time 1 wellbeing was highly significant in every analysis (all $p$ 's $<0.01$ ), indicating considerable rank-order stability, presumably reflecting the set point and stable personality differences. Activity change was also significant in every analysis, and circumstantial change was significant in all but the NA analysis.

Next, we tested our primary hypothesis - that is, that positive activity change would predict well-being at Time 3 , whereas activity change would not. Specifically, we regressed the Time 3 well-being variables on the corresponding Time 1 well-being variables and also the two change variables. Table III also

TABLE III

Standardized coefficients predicting change in well-being (Study 2)

\begin{tabular}{lcc}
\hline & Time 2 & Time 3 \\
\hline $\begin{array}{l}\text { Subjective well-being } \\
\text { Time 1 subjective well-being }\end{array}$ & $0.66^{*}$ & $0.56^{*}$ \\
$\begin{array}{l}\text { Being } \\
\text { Activity change }\end{array}$ & $0.12^{*}$ & $0.12^{*}$ \\
Circumstantial change & $0.10^{*}$ & 0.01 \\
Positive affect & & \\
Time 1 positive affect & $0.48^{*}$ & $0.44^{*}$ \\
Activity change & $0.16^{*}$ & $0.16^{*}$ \\
Circumstantial change & $0.16^{*}$ & 0.05 \\
Negative affect & & \\
Time 1 negative affect & $0.54^{*}$ & $0.45^{*}$ \\
Activity change & $-0.09^{*}$ & -0.05 \\
Circumstantial change & -0.05 & 0.03 \\
Life satisfaction & & \\
Time 1 life satisfaction & $0.74^{*}$ & $0.68^{*}$ \\
Activity change & $0.07^{*}$ & $0.10^{*}$ \\
Circumstantial change & $0.07^{*}$ & 0.03 \\
\hline
\end{tabular}

$* p<0.01$. 
contains these results. Time 1 well-being was again highly significant in every analysis (all $p$ 's $<0.01$ ). However, as predicted, only activity change was significant in the SWB analysis, whereas circumstantial change fell to non-significance. Circumstantial change was also non-significant for each individual SWB variable, whereas activity change was significant for PA and life-satisfaction but not NA.

\section{Mean-Level Shifts}

The analyses reported above concerned rank-order shifts in well-being. Next, we considered the within-subject means that resulted from the two types of change, focusing on the aggregate SWB variable. First, we created two difference scores by subtracting Time $1 \mathrm{SWB}$ from Time $2 \mathrm{SWB}$, and Time 1 SWB from Time $3 \mathrm{SWB}$. This allowed us to consider each participant's variations from his or her initial SWB baseline at each of the two follow-up periods. Next, we normalized the activity change and circumstantial change variables from a 5-point to a 3-point scale, thereby creating balanced groups in the low and high ends of each distribution. ${ }^{2}$

We then conducted two ANOVAs, one for each change variable, in which amount of activity or circumstantial change (low, medium, or high) was a between-subjects factor with three levels, and comparison period (from $\mathrm{T} 1$ to $\mathrm{T} 2$, or from $\mathrm{T} 1$ to $\mathrm{T} 3$ ) was a within-subjects factor with two levels. The two panels of Figure 1 present the means produced in each analysis. As can be seen, in the activity change analysis (top panel), the low and medium change groups declined in SWB between Time 1 and Time 2, and stayed at this lower level at Time 3. However, the high activity change group essentially maintained their initial levels, at both Time 2 and Time 3. There were no significant main effects of amount of change or of time period, and no significant interaction between the two factors (all $p$ 's $>0.10$ ). In the circumstantial change analysis (bottom panel), the low change group declined the most in SWB from Time 1 to Time 2 , then somewhat bounced back. The medium change group declined somewhat less, then maintained the lower level. The high change group declined the least at first, but then declined more from Time 2 to Time 3 . These variable patterns of change 

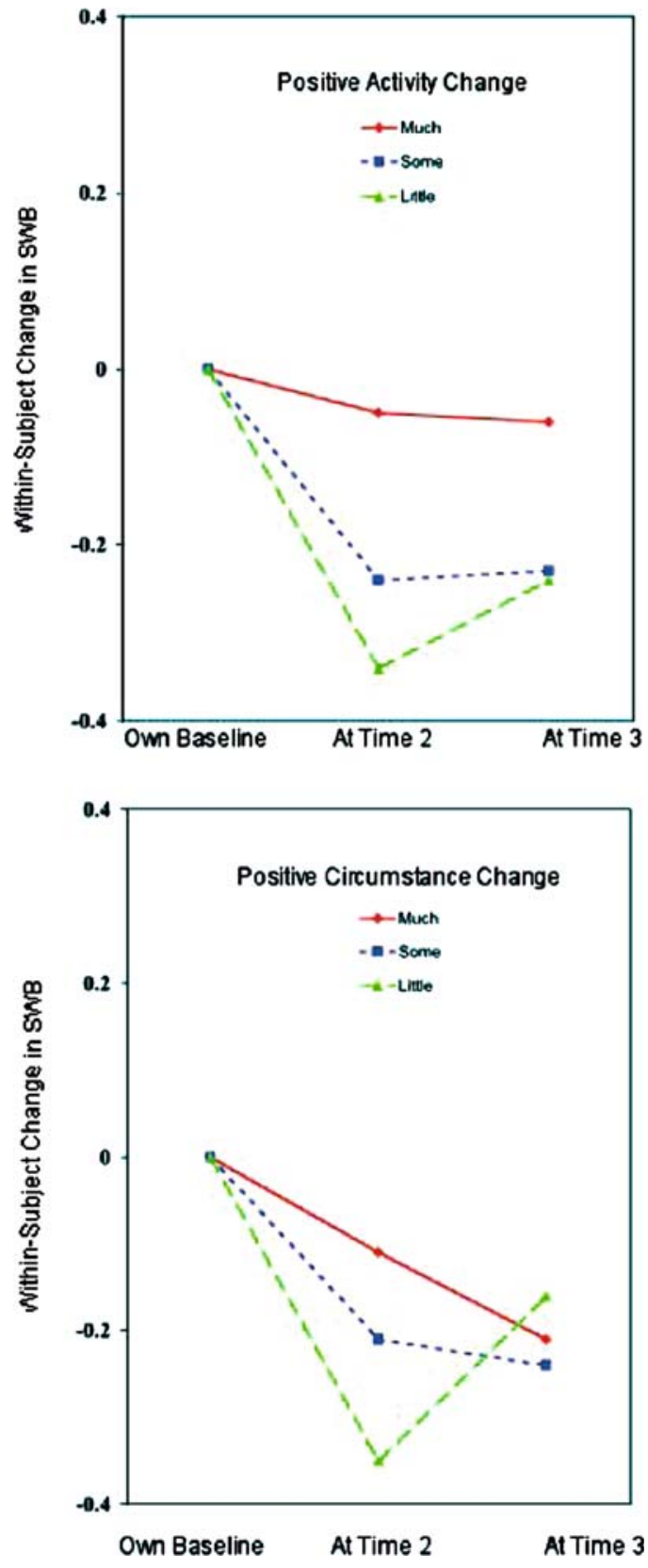

Figure 1. Longitudinal differences in SWB by amount of life change and type of life change - positive activity change (top panel) and positive circumstance change (bottom panel) (Study 2). 
were reflected in a significant Amount of Change $\times$ Time Period interaction, $F_{(2,666)}=5.28, p<0.01$; neither main effect was significant.

\section{BRIEF DISCUSSION}

Study 2 provided support for our dynamic process model of longitudinal well-being. Although positive circumstantial change predicted a positive rank-order shift in well-being at Time 2 , it was not associated with well-being at a third assessment, near the end of the semester. Again, we assume that this occurred in part because of hedonic adaptation to positive circumstantial change, such that participants no longer noticed or benefited from these changes. In contrast, activity change predicted rankorder gains between Time 1 and Time 2 and also predicted maintenance of these gains at Time 3. Again, we assume that this occurred in part because of the steady stream of positive experiences induced by activity change. Notably, the two types of life change exerted larger effects on enhancing positive wellbeing (i.e., by promoting rank-order increases in positive mood and life satisfaction), than they did on ameliorating negative well-being (i.e., by promoting rank-order decreases in negative mood).

Examination of mean-level patterns revealed that the highest positive activity change group did not actually succeed in boosting their levels of well-being - instead, they largely maintained their initial levels. Although sustaining one's previous level of well-being may not seem as desirable or noteworthy as increasing one's well-being beyond one's previous level, we believe that the ability to "maintain the initial glow" of the semester is a significant achievement. In other words, amid circumstances in which one's cohort is experiencing stress and declining wellbeing, our model may best describe a process of resilience by which this general pattern is avoided. In contrast, when one's cohort is experiencing "good times" and sample-wide increases in well-being (e.g., during summer vacation), presumably, our model would pinpoint those who experienced the largest boosts of all. 


\section{STUDY 3}

In Study 3, we sought to replicate the basic Study 2 findings concerning changes in SWB (Diener, 1984, 1994). However, we included additional measures of well-being, to evaluate the breadth of the phenomenon identified in Study 2. Specifically, we additionally assessed psychological well-being (PWB; Ryff and Keyes, 1995; Keyes et al., 2002), which includes more global measures of personal and psychosocial thriving, including relationship-satisfaction, mastery, purpose, self-acceptance, personal growth, and autonomy. Keyes and his colleagues (2002) have shown that these constructs perform somewhat differently than the conventional SWB measures employed in Study 2. However, we believed that our model should apply to PWB as well, because activity changes can presumably enhance one's sense of mastery, relatedness, and purpose. Finally, we included Lyubomirsky and Lepper's (1999) measure of subjective happiness, to directly address the question posed by the title of this article and to tap into a more global, molar well-being construct, which more closely matches what most laypeople are trying to pursue. We expected our model to apply to this measure as well.

As a further change in Study 3, we broadened our assessment of activity and circumstantial changes beyond the single item measures used in Study 2. That is, changes in specific types of circumstances and specific types of activities were assessed. In so doing, we hoped to further validate our assumption that these represent two distinct categories of life change.

\section{METHOD}

\section{Participants and Procedure}

Participants were 275 students in a psychology class, who took part for extra course credit. As in Study 2, questionnaires were administered in class at three points during the semester. The final sample for the study comprised 204 participants (136 women and $68 \mathrm{men}$ ), who completed all three questionnaires. 


\section{Measures}

As in Study 2, participants completed the PANAS and the SWLS at three points during the semester, and an aggregate SWB variable was computed for each time of measurement by adding PA and life satisfaction, and subtracting NA. Again, factor analyses supported this procedure, as a single factor was found at each time period, accounting for $64 \%, 59 \%$, and $59 \%$ of the variance, respectively. In addition, participants completed the 4-item Subjective Happiness Scale at each time period (Lyubomirsky and Lepper, 1999; $\alpha$ 's $=0.80,0.80$, and 0.81). Finally, on each occasion, participants completed the PWB scale (Ryff and Keyes, 1995; Keyes et al., 2002), an 18-item measures of psychosocial thriving ( $\alpha$ 's $=0.78,0.81$, and 0.83 ).

To assess both circumstantial and activity change between Time 1 and Time 2, we administered the same paragraphs employed in Study 2. However, for each change variable, we also included three other, more specific, items. For circumstantial change, these new items were as follows: "To what extent has your monetary situation changed in the past 6 weeks (i.e., you have gained or lost money)?," "To what extent have your living arrangements changed in the past 6 weeks (i.e., you live in a better/worse place, or with a better/worse roommate)?," and "To what extent has your relationship status changed in the past 6 weeks (i.e., you have acquired or lost a boyfriend/ girlfriend)?" For activity change, the additional three items were the following: "To what extent have your goals, projects, or strivings changed in the past 6 weeks?"; "To what extent has your diet, exercise, or other self-maintenance activity changed in the past 6 weeks?"; and "To what extent have your conscious attitudes or mental approach to life changed in the past 6 weeks?" For each change variable, four items (the additional three items, plus the item used in Study 2) were averaged to form an aggregate circumstantial change variable and an aggregate activity change variable.

A principal components analysis of the eight items revealed a clean two-factor solution, with each item loading on the expected factor at 0.56 or more, with no cross-loading greater than 0.24 . These analyses support our contention that activity and circumstantial changes are empirically distinct constructs. 
Still, the two factors only accounted for $44 \%$ of the variance, and the alpha coefficients were low for the two composites ( $\alpha$ 's $=0.60$ and 0.47 , respectively). However we believe this is understandable given that people would not be expected to report experiencing every activity change or every circumstantial change on the list. What is most important is the number of such changes endorsed, and the fact that the two types of change were empirically distinct. Nunnally and Bernstein (1994) coined the term "emergent construct" to refer to such measures, which additively combine items that may not be highly correlated themselves.

\section{RESULTS}

\section{Preliminary Analyses}

As in Study 2, we first assessed sample-wide well-being changes over the semester. Table IV contains the relevant means. In contrast to Study 2, no sample-wide changes were observed (all $t$ 's $<1.52$ ). In a second preliminary analysis, the activity change and circumstantial change variables were found to have a weaker association than in Study $2(r=0.20, p<0.01)$, further suggesting that they are distinct constructs, especially when measured with multiple items.

TABLE IV

Descriptive statistics for Study 3 measures

\begin{tabular}{lll}
\hline & Mean & Standard deviation \\
\hline Positive activity change & 3.60 & 0.56 \\
Positive circumstantial change & 3.10 & 0.59 \\
T1 Subjective well-being & 5.10 & 1.86 \\
T2 Subjective well-being & 5.14 & 1.64 \\
T3 Subjective well-being & 4.98 & 1.84 \\
T1 Happiness & 3.57 & 0.77 \\
T2 Happiness & 3.59 & 0.74 \\
T3 Happiness & 3.63 & 0.77 \\
T1 Psychological well-being & 3.99 & 0.42 \\
T2 Psychological well-being & 3.99 & 0.42 \\
T3 Psychological well-being & 3.98 & 0.45 \\
\hline
\end{tabular}


TABLE V

Standardized coefficients predicting change in well-being (Study 3)

\begin{tabular}{lll}
\hline & Time 2 & Time 3 \\
\hline Subjective well-being & & \\
Time 1 Subjective well-being & $0.64^{*}$ & $0.48^{*}$ \\
Activity change & $0.19^{*}$ & $0.19^{*}$ \\
$\begin{array}{l}\text { Circumstantial change } \\
\text { Happiness }\end{array}$ & $0.12^{*}$ & 0.03 \\
Time 1 happiness & $0.64^{*}$ & $0.59^{*}$ \\
Activity change & $0.24^{*}$ & $0.18^{*}$ \\
Circumstantial change & $0.16^{*}$ & 0.07 \\
Psychological well-being & & \\
Time 1 psychological well-being & $0.71^{*}$ & $0.68^{*}$ \\
Activity change & $0.15^{*}$ & $0.15^{*}$ \\
Circumstantial change & 0.06 & 0.06 \\
\hline
\end{tabular}

$* p \leqslant 0.01$.

\section{Primary Analyses}

Rank-order analyses

We tested the same regression models as in Study 2, separately for SWB, PWB, and happiness. As shown in Table V, both activity changes and circumstantial changes predicted rank-order gains in SWB at Time 2, controlling for Time 1. In addition, both types of changes predicted rank-order gains in happiness at Time 2 . However, only activity changes reached significance in predicting changes in PWB at Time 2, whereas circumstantial changes did not predict enhanced PWB. Turning to Time 3, only activity changes predicted maintained gains at Time 3 , for all three outcomes; circumstantial changes were non-significant in every case. Thus, these data replicate the dynamic patterns shown in Study 2 , extending them to two new measures of well-being.

Mean-level analyses

Next, we examined the issue of mean-level change in SWB, happiness, and PWB. However, because activity and circumstantial changes were measured via multi-item composites instead of single items, we could not employ the categorical ANOVA approach described in Study 2. Instead, we used the regression 
models described above to compute predicted means for two representative persons: one who started out at Time 1 with a level of SWB equal to the sample mean who then experienced activity changes one standard deviation above the mean and circumstantial changes at the mean, and another who also started out at the sample mean who then experienced circumstantial changes one standard deviation above the mean and activity changes at the mean. This enabled us to examine the trajectories of those who made significant activity changes in combination with an average degree of circumstantial change, and vice versa.

Figure 2 contains the SWB trajectories for those making above-average circumstantial changes and average activity changes, and for those making above-average activity changes and average circumstantial changes. As can be seen, those making above-average activity changes increased in their mean levels of SWB, and then maintained most of the gain. Those making above-average circumstantial changes increased in their mean levels of SWB, then lost all of that gain. The pattern for the happiness construct was quite similar to that depicted in Figure 2, with a peak and subsequent decline for those making

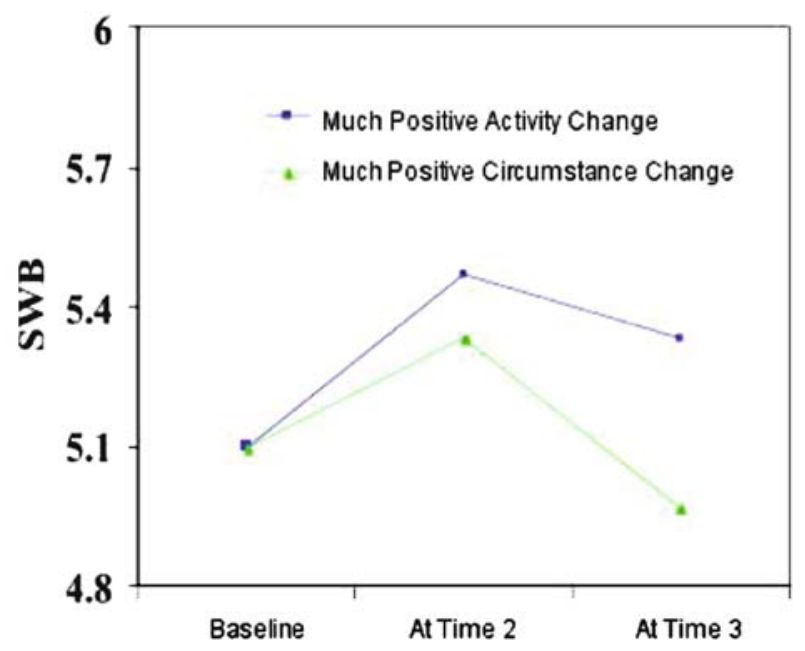

Figure 2. Predicted changes in SWB for those reporting very positive activity changes at Time 2 , and those reporting very positive circumstantial changes at Time 2 (Study 3). 
circumstantial changes, and a maintained peak for those making activity changes. The pattern for the PWB construct was also the same for the activities group, but was somewhat different for the positive circumstantial changes group, which manifested a flat trajectory throughout the semester on this measure.

\section{BRIEF DISCUSSION}

Study 3 replicated Study 2's most important finding - namely, that activity changes lead to maintainable rank-order increases in SWB, and circumstantial changes do not. In addition, Study 3 generalized the basic effect to measures of subjective happiness (Lyubomirsky and Lepper, 1999) and psychological or psychosocial well-being (Ryff and Keyes, 1995). Furthermore, Study 3 broadened the measurement of the activity change and circumstantial change constructs. Finally, Study 3 suggested that activity changes can lead to sustainable gains in absolute levels of well-being, as well as sustainable rank-order gains in well-being.

\section{GENERAL DISCUSSION}

These studies tested an important proposition of Lyubomirsky and colleagues' (2005) longitudinal model of well-being. Again, the model distinguishes between two types of beneficial life changes, circumstantial changes and activity changes, reflecting theoretical distinctions often employed in the SWB literature. Although both types of change are assumed by the model to positively influence well-being in the short-term, the effects of circumstantial change are postulated to be less enduring, because of hedonic adaptation. The current studies found clear and consistent support for this prediction, not only for subjective well-being (positive affect, negative affect, and life satisfaction), but also, for subjective happiness (Lyubomirsky and Lepper, 1999), and for psychological well-being (Ryff and Keyes, 1995). 
We believe these findings have important implications for a controversial, and under-studied, issue in well-being research (Lucas et al., 2003). Can a person sustainably increase her level of well-being, or is she doomed to return to her genetic set point, after any temporary change? If the latter perspective is correct, then positive psychology research, the "self-help" movement, and the American dream more generally may offer only empty promises. However, if well-being boosts are indeed sustainable over the long-term, then it becomes imperative to understand how this may be done. The current studies offer promising new information concerning this question.

Can positive circumstantial changes have no sustainable impact on well-being? This conclusion is probably an overstatement. First, it is undoubtedly necessary to achieve a threshold of basic positive circumstances before one can concentrate on the "better things" in life (Oishi et al., 1999). In other words, under extremely unfavorable or impoverished conditions, changing one's circumstances (i.e., acquiring a safe place to live and a secure source of sustenance) can have large effects on well-being, although such changes may only get one to one's set point, and not above it. Second, even assuming that an individual has already met his basic needs, it may be possible for him to further improve his well-being via further circumstantial changes. However, we believe this is feasible only to the extent that one takes action to keep the new circumstances "fresh" i.e., by remembering to appreciate or feel gratitude for them, or by making the effort to take advantage of the opportunities for positive experiences that they afford. In other words, this is feasible when one engages in intentional activity with respect to the circumstances in one's life - that is, when one acts upon one's circumstances.

How sharp is the distinction between activity change and circumstantial change? This is an important question, because obviously, many circumstantial changes are brought about by intentional activity, and many intentional activities are dependent on circumstances. Despite the potentially fuzzy boundary between them, the two constructs were not highly correlated ( $r$ 's $=0.31$ and 0.20 in Studies 2 and 3), and also yielded distinct and differential results in the current research, as predicted 
by our theory and past findings in the well-being literature. Indeed, the clear and strong group differences found in Study 1 suggest that our participants had little difficulty understanding and distinguishing between circumstances and activities. Perhaps what is most critical is not the objective life change that occurs, but, rather, each individual's subjective construal of that change. That is, the same event (e.g., getting married) can signify to one person a circumstance to which she adapts quickly, but, to another person, an intentional activity that can give rise to a diverse stream of positive experiences.

\section{Limitations and Remaining Questions}

These studies have several limitations. First, we only examined three waves of data in Studies 2 and 3, and the full model test focused on a relatively short period of time (i.e., one semester). Thus, it remains to be seen whether the positive activity effects demonstrated herein would persist across further waves of data, collected over a longer period of time. A second limitation was that we did not evaluate the many possible moderators of the activity-change effects. Adopting a new goal or program of activity may not do one any good if the activity does not fit one's needs, predispositions or talents, if one pursues the activity for the "wrong" reasons, if one fails to do well at the activity, or if one practices the activity in a monothematic or invariant way. In short, it is undoubtedly necessary to select appropriate activities, to attend to the optimal timing, variety, and other factors in the way that one practices them, and to do reasonably well at them (Lyubomirsky et al., in press). We believe such unmeasured moderators can help explain the somewhat modest change main effects observed herein, and represent a promising future research direction.

Third, the present research does not establish the generalizability of the effects to people of other ages, socioeconomic statuses, or cultural memberships. Perhaps such factors affect the ease with which people are able to make activity-based life changes, or affect how much influence circumstantial and activity-based changes have on peoples' well-being. Furthermore, future researchers should collect more objective measures of well-being, involving peer report or objective 
psychosocial functioning. Finally, it would be fruitful in the future to expand the assessment of activity and circumstantial changes, to better represent these important categories of effects upon well-being.

Finally, we did not attempt to measure the happiness set point in this research, although it is an important part of our theoretical model. We assumed that the set point's influence is largely constant and is represented by each participant's mean level across the multiple well-being assessments. However, future researchers might attempt to explicitly model the set point, perhaps using some combination of existing personality measures, or by measuring an individual's average well-being over many years (Lykken, 1999), or perhaps by assessing a weighted average of the well-being of a given participant's biological family members. Although using such measures to predict mean levels of well-being over time is a potentially important enterprise, it is one that is largely orthogonal to the current research, which focused on variations in well-being over time.

\section{CONCLUSION}

A central presumption of the "American dream" is that, through their own efforts and hard work, people may move towards greater happiness and fulfillment in life. This assumption is echoed in the writings of philosophers, both ancient and modern. In Nicomachean Ethics, Aristotle (1985) proposed that happiness involves engagement in activities that promote one's highest potentials. And, in the Conquest of Happiness, Bertrand Russell (1930/1975) argued that the secrets to happiness include enterprise, exploration of one's interests, and the overcoming of obstacles. The current studies provide important new support for these ideas. But do they also glorify the ideals of pleasure and self-gratification, which are also endemic to American culture? We believe not. Indeed, the fact that activity changes require considerable effort to enact is more consistent with the Puritan version of the American dream, rather than the "easy living" or the "quick fix" ideals that have partially supplanted this foundational vision. In other words, our data suggest that effort and hard work offer the most promising route to 
happiness. In contrast, simply altering one's superficial circumstances (assuming they are already reasonably good) may have little lasting effect on personal well-being. We believe these are potentially potent prescriptions to keep in mind.

\section{NOTES}

1 Notably, the effects reported below are still significant, albeit somewhat weaker, when the full sample is used.

2 Specifically, our change variables were recoded as follows: activity change variable $(1=1 ; 2=1 ; 3=2 ; 4=2 ; 5=3)$ and circumstantial change variable $(1=1 ; 2=1 ; 3=2 ; 4=3 ; 5=3)$. This resulted in $n$ s of 116,447 , and 106 for three levels of the activity change variable, and $n$ s of 216, 269, and 184 for three levels of the circumstantial change variable.

\section{REFERENCES}

Aristotle, M.: 1985, Nicomachean Ethics. (T. Irwin, Trans.) (Hackett, Indianapolis IN).

Argyle, M.: 1999, Causes and correlates of happiness, in D. Kahneman E. Diener and N. Schwarz (eds), Well-being: The Foundations of Hedonic Psychology (Russell Sage Foundation, New York), pp. 353-373.

Atkinson, T.: 1982, 'The stability and validity of quality of life measures', Social Indicators Research 10, pp. 113-132.

Bandura, A.: 1997, Self-efficacy: The Exercise of Control (Freeman, New York).

Brickman, P. and D.T. Campbell: 1971, Hedonic relativism and planning the good society, in M.H. Appley (ed.), Adaptation-level Theory (Academic Press, New York), pp. 287-302.

Brickman, P., D. Coates and R. Janoff-Bulman: 1978, 'Lottery winners and accident victims: Is happiness relative?', Journal of Personality and Social Psychology 36, pp. 917-927.

Brunstein, J.C., O.C. Schultheiss and R. Grassman: 1998, 'Personal goals and emotional well-being: The moderating role of motive dispositions', Journal of Personality and Social Psychology 75, pp. 494-508.

DeNeve, K.M. and H. Cooper: 1998, 'The happy personality: A meta-analysis of 137 personality traits and subjective well-being', Psychological Bulletin 124, pp. 197-229.

Diener, E.: 1984, 'Subjective well-being', Psychological Bulletin 95, pp. $542-575$. 
Diener, E.: 1994, 'Assessing subjective well-being: Progress and opportunities', Social Indicators Research 31, pp. 103-157.

Diener, E., R. Emmons, R. Larsen and S. Griffin: 1985, 'The Satisfaction with Life Scale', Journal of Personality Assessment 47, pp. 1105-1117.

Diener, E. and R.E. Lucas: 1999, Personality and subjective well-being, in D. Kahneman, E. Diener and N. Schwartz (eds), Well-being: The Foundations of Hedonic Psychology (Russell Sage, New York), pp. 213-229.

Diener, E., E.M. Suh, R.E. Lucas and H.L. Smith: 1999, 'Subjective well-being: Three decades of progress', Psychological Bulletin 125, pp. 276-302.

Diener, E., E.M. Suh, H. Smith and L. Shao: 1995, 'National differences in reported well-being: Why do they occur?', Social Indicators Research 34, pp. 7-32.

Dijkers, M.: 1997, 'Quality of life after spinal cord injury: A meta-analysis of the effects of disablement components', Spinal Cord 32, pp. 829-840.

Elliot, A.E. and K.M. Sheldon: 1996, 'Avoidance achievement motivation: A personal goals analysis', Journal of Personality and Social Psychology 7, pp. $667-679$.

Emmons, R.A. and L.A. King: 1988, 'Conflict among personal strivings: Immediate and long-term implications for psychological and physical wellbeing', Journal of Personality and Social Psychology 54, pp. 1040-1048.

Emmons, R.A. and M.E. McCullough: 2003, 'Counting blessings versus burdens: An experimental investigation of gratitude and subjective well-being in daily life', Journal of Personality and Social Psychology 84, pp. 377-389.

Fava, G.: 1999, 'Well-being therapy: Conceptual and technical issues', Psychotherapy and Psychosomatics 68, pp. 171-179.

Fordyce, M.W.: 1977, 'Development of a program to increase happiness', Journal of Counseling Psychology 24, pp. 511-521.

Fordyce, M.W.: 1983, 'A program to increase happiness: Further studies', Journal of Counseling Psychology 30, pp. 483-498.

Frederick, S. and G. Loewenstein: 1999, Hedonic adaptation, in D. Kahneman, E. Diener and N. Schwarz (eds), Well-being: The foundations of hedonic psychology (Russell Sage Foundation, New York), pp. 302-329.

Fredrickson, B.L. and T. Joiner: 2002, 'Positive emotions trigger upward spirals toward emotional well-being', Psychological Science 13, pp. 172-175.

Freedman, J.: 1978, Happy people: What happiness is, who has it, and why (Harcourt Brace Jovanovich, New York).

Headey, B. and A. Wearing: 1989, 'Personality, life events, and subjective wellbeing: Toward a dynamic equilibrium model', Journal of Personality and Social Psychology 57, pp. 731-739.

Kahneman, D.: 1999, Objective happiness, in D. Kahneman, E. Diener N. Schwarz (eds), Well-being: The Foundations of Hedonic Psychology (Russell Sage Foundation, New York), pp. 3-25.

Kasser, T. and R.M. Ryan: 1993, 'A dark side of the American dream: Correlates of financial success as a central life aspiration', Journal of Personality and Social Psychology 65, pp. 410-422. 
Kasser, T. and R.M. Ryan: 1996, 'Further examining the American dream: Differential correlates of intrinsic and extrinsic goals', Personality and Social Psychology Bulletin 22, pp. 280-287.

Keyes, C.L.M., D. Shmotkin and C.D. Ryff: 2002, 'Optimizing well-being: The empirical encounter of two traditions', Journal of Personality and Social Psychology 82, pp. 1007-1022.

King, L.A.: 2001, 'The health benefits of writing about life goals', Personality and Social Psychology Bulletin 27, pp. 798-807.

Lichter, S, K. Haye and R. Kammann: 1980, 'Increasing happiness through cognitive retraining', New Zealand Psychologist 9, pp. 57-64.

Lucas, R.E., A.E. Clark, Y. Georgellis and E. Diener: 2003, 'Reexamining adaptation and the set point model of happiness: Reactions to changes in marital status', Journal of Personality and Social Psychology 84, pp. $527-539$.

Lykken, D.: 2000, Happiness: The nature and nurture of joy and contentment (St. Martin's Griffin, New York).

Lykken, D. and A. Tellegen: 1996, 'Happiness is a stochastic phenomenon', Psychological Science 7, pp. 186-189.

Lyubomirsky, S. and H.S. Lepper: 1999, 'A measure of subjective happiness: Preliminary reliability and construct validation', Social Indicators Research 46, pp. 137-155.

Lyubomirsky, S. and L. Ross: 1997, 'Hedonic consequences of social comparison: A contrast of happy and unhappy people', Journal of Personality and Social Psychology 73, pp. 1141-1157.

Lyubomirsky, S., Sheldon, K.M., Schkade, D., 2005, 'Pursuing happiness: The architecture of sustainable change', Review of General Psychology 9, pp. 111-131.

Lyubomirsky, S., Sousa, L, Dickerhoof, R.: 2004. 'The medium is the message: The costs and benefits of thinking, writing, and talking about life's triumphs and defeats', Manuscript submitted for publication.

McCrae, R.R. and P.T. Costa: 1994, 'The stability of personality: Observations and evaluations', Current Directions in Psychological Science 3, pp. $173-175$.

McCullough, M.E., Pargament, K.I. and Thoresen C.E., (eds): 2000, Forgiveness: Theory, Research, and Practice (New York: The Guilford Press).

McGregor, I. and B.R. Little: 1998, 'Personal projects, happiness, and meaning: On doing well and being yourself', Journal of Personality and Social Psychology 74, pp. 494-512.

Nunnally, J.C. and I.H. Bernstein: 1994, Psychometric Theory (3rd ed.) (McGraw-Hill, New York).

Oishi, S., E.F. Diener, R.E. Lucas and E.M. Suh: 1999, 'Cross-cultural variations in predictors of life satisfaction: Perspectives from needs and values', Personality and Social Psychology Bulletin 25, pp. 980-990.

Parducci, A.: 1995, Happiness, Pleasure, and Judgment: The Contextual Theory and its Applications (Erlbaum, Hove, England). 
Russell, B.: 1975, The Conquest of Happiness (London: Unwin - original work published 1930).

Ryff, C.D. and C.L.M. Keyes: 1995, 'The structure of psychological well-being revisited', Journal of Personality and Social Psychology 69, pp. 719-727.

Schulz, R.: 1976, 'Effects of control and predictability on the physical and psychological well-being of the institutionalized aged', Journal of Personality and Social Psychology 33, pp. 563-573.

Scitovsky, T.: 1976, The Joyless Economy: The Psychology of Human Satisfaction (Oxford University Press, New York).

Seligman, M.E.P.: 1991, Learned Optimism (A. A. Knopf, New York).

Sheldon, K.M. and A.J. Elliot: 1999, 'Goal striving, need-satisfaction, and longitudinal well-being: The Self-Concordance Model', Journal of Personality and Social Psychology 76, pp. 482-497.

Sheldon, K.M. and L. Houser-Marko: 2001, 'Self-concordance, goal-attainment, and the pursuit of happiness: Can there be an upward spiral?', Journal of Personality and Social Psychology 80, pp. 152-165.

Sheldon, K.M. and T. Kasser: 1995, 'Coherence and congruence: Two aspects of personality integration', Journal of Personality and Social Psychology 68, pp. $531-543$.

Sheldon, K.M., T. Kasser, K. Smith and T. Share: 2002, 'Personal goals and psychological growth: Testing an intervention to enhance goal-attainment and personality integration', Journal of Personality 70, pp. 5-31.

Taylor, S.E. and J.D. Brown: 1988, 'Illusion and well-being: A social psychological perspective on mental health', Psychological Bulletin 103, pp. 193-210.

Watson, D., A. Tellegen and L. Clark: 1988, 'Development and validation of brief measures of positive and negative affect: The PANAS scales', Journal of Personality and Social Psychology 54, pp. 1063-1070.

Address for correspondence:

KENNON M. SHELDON

University of Missouri

$65211 \mathrm{MO}$

Columbia

E-mail:SheldonK@missouri.edu

SONJA LYUBOMIRSKY

University of California

Riverside CA 92521

USA

E-mail: Sonja@cirtrus.ucr.edu 